\title{
Effective Utilization of Prosopis Juliflora for Cooking Purposes Through Gasification Technology
}

\author{
S. Sindhujarajan \\ Dept. of Bioenergy, \\ Tamil Nadu agricultural University \\ Coimbatore, India
}

\author{
Dr. S. Kamaraj \\ Dept. of Bioenergy, \\ Tamil Nadu Agricultural University \\ Coimbatore, India
}

\begin{abstract}
Gasification involves the conversion of biomass feedstock to useful products such as biochar and producer gas with the latter being used for cooking purposes. The feedstock selection is critical for gasification that can address the social concerns such as land availability for the feedstock growth. Hence, this paper aims at testing Prosopis Juliflora (PJ) as an effective feedstock for the gasifiers. In traditional wood fired stoves, PJ is recently preferred for fuel wood due to its high calorific value and growth rate, cycling time of six years (comparable to any other fuel wood species), coppicing power and its capability to produce more extensive root system and deeper penetration to rehabilitate sodic soils more effectively. The characteristics such as moisture content, volatile matter and ash content of PJ were $9.3 \%, 83.05 \%$ and $1.7 \%$ respectively. The calorific value was $4952 \mathrm{kcal} / \mathrm{kg}$ and these characteristics make PJ as an effective feedstock for the gasification process. Further TGA analysis confirms the feasibility of $P J$ as a suitable candidate for gasification. The composition of the producer gas produced during the gasification was dominated by carbon monoxide (20\%), hydrogen (12\%), nitrogen $(45.3 \%)$, carbon dioxide $(17.5 \%)$ and methane $(3.25 \%)$. The gas was scrubbed using a fabric filter to remove the tar content thereby reducing tar coagulation in the stove and to increase the thermal efficiency of the gas.
\end{abstract}

Keywords - Gasification, biomass, producer gas, combustion, fibre filter

\section{INTRODUCTION}

Traditional community cooking stoves have a low level of efficiency due to their poor heat transfer efficiency and incomplete combustion. The low efficiency results in a high consumption of fuel wood, thereby creating a need of more fuel wood [1]. In the past few decades lot of research has been focused on the development of better cooking stoves for burning biomass, but the magnitude of the problem is still a major cause of concern [2]. In these traditional cooking stoves the biomass is combusted directly to release heat energy thereby reducing the thermal efficiency of the stoves. In order to increase the heat transfer efficiency and to reduce the fuel wood consumption direct combustion gasification technique is employed in this study. Biomass is one such source to provide sustainable supply of the required energy through producer gas, biogas, biodiesel, etc [3]. The substitution of conventional fossil fuels with biomass for energy production results both in a net reduction of greenhouse gases emission and in the replacement of nonrenewable energy sources [4]. Biomass energy conversion technologies especially pyrolysis and gasification have been substantially studied to promote renewable energy utilization and solving partially the environmental issues [5] Gasification is an advanced thermo-chemical process. In this process, the fuel is ignited by partial supply of oxidant (30-40 $\%$ of the stoichiometric requirement). Different processes and operations occurring in the gasifier reactor are mainly in four reaction zones (i.e., oxidation, reduction, pyrolysis and drying) [8]. When air is used as an oxidant, the product is referred to as producer gas. It consists of carbon monoxide (20-22\%), hydrogen $(10-12 \%)$, methane (1-2\%), nitrogen $(50-55 \%)$ and carbon dioxide (10\%). Char and Tar also produced in gasification [7].Various types of gasification systems have been developed and some of them are commercialized. Yang et al. [5] concluded that fixed bed gasification is the most common technology for the energy use of biomass and solid municipal wastes.

The primary biomass selected for gasification in this study is Prosopis Juliflora $(P J)$. The main reason for testing the effective of this biomass for gasification is that the area selected for this study has extensive production of $P J$, as it is a very hardy plant that grows very fast even in water scarce area and is ready for harvest within 2- 3 years. The harvested plant grows back to its original size in 16 to 18 months and has a calorific value close to $3,600-4,000 \mathrm{kcal} / \mathrm{kg}$ making it the most suitable biomass fuel [6]. The $P J$ also has an advantage of low moisture and ash content that can be harnessed for various applications. In the present days there is scarcity for fossil fuels and due to global warming today's technology is shifting to renewable energy. Also, the Government of India's Planning Commission predicts dramatic demand increases for coal and oil over the next 20 years [9]. For thermal application and power generation the main problem is biomass availability most of them they rely on coconut shell, ground nut shell.

The gasification system can be physically isolated from the combustion system \& the producer gas can be piped from the gasifier (which may be located outside the plant building) to the ovens/furnaces etc located in the plant building. This makes the handling of fuel and ash removal from the gasifier easy and can be done away from the actual working area. The producer gas produced by gasifier can be burnt in specially designed burners, so that the fossil fuels such as F.O/L.D.O/Diesel/LPG/CNG. Thus, expensive liquid/gas fuels can be effectively replaced by low cost wood/biomass without any changes in operations, temperature profile, temperature control and cleanliness in the plant area. 


\section{MATERIALS AND METHODS}

This study deals with performance evaluation of downdraft gasifier for thermal application. The feedstock used in this study was Prosopis Juliflora.

\section{A. Description of gasifier system}

The biomass based gasifier system is $100 \mathrm{~kg} / \mathrm{hr}$ rated capacity. The system consists of gasifier, fabric filters, suction blower, and wet scrubber.

\section{B. Gasifier}

Open top, twin air entry system, which ensure a better thermal environment compared to the conventional closed top model. Uses staged air injection. Multi-fuel capability-wood residues and agro residues in briquetted form with moisture content less than $12 \%$. The gasifier produces producer gas with high gasification efficiency $>85 \%$ with biomass consumption between 1.1-1.2 kg/KWH. The gas outlet of the gasifier is connected with the wet scrubber for cleaning purposes.

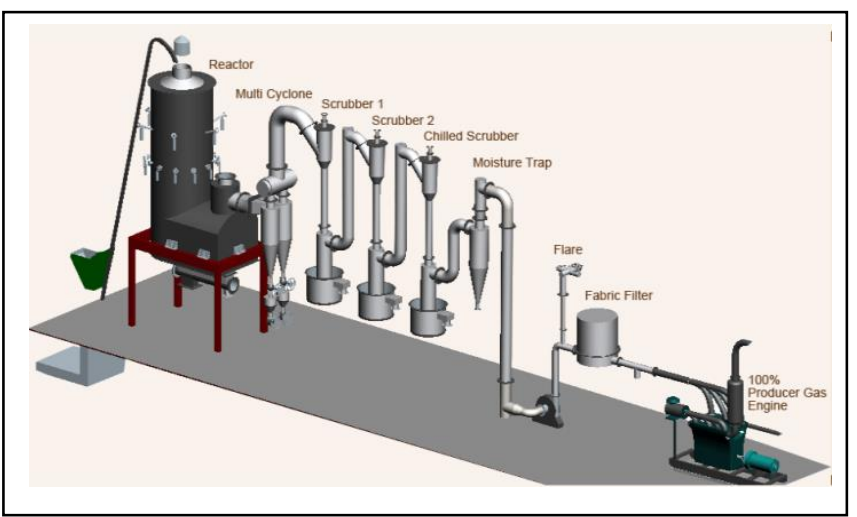

Fig. 1. Schematic diagram of the gasifier used for the gasification experiments

\section{Cleaning system - Wet scrubber}

The gas produced from the gasifier contains dust particle and tar. The gas emitted from the gasifier is sent to the chilled scrubber also known as the wet scrubber. Effective gas cleaning system which provides gas with less than $15 \mathrm{ppm}$ of suspended particulate matter to meet the quality standards set by engine manufacturers. The temperature of the gas emitted from the gasifier is around $600^{\circ} \mathrm{C}-700^{\circ} \mathrm{C}$. This scrubber not only cools the gas and also helps in removing the light particles present in the gas. The wet scrubber completely removes heavy particulates. The gas is cooled and sent to the filters. The saw dust is used as a filtering medium. The gas is passed through the medium in which tar for the gas has been removed. After the removal of tar from the gas, it was again passed through the fabric filter for the removal of residual dust particles. Finally the cleaned producer gas was used for cooking purposes.

\section{Suction blower}

Air blowers generally uses centrifugal force to propel the air forward. Inside a centrifugal air blower is a wheel with small blades on the circumference and a casing to direct the flow of air into the center of the wheel and out toward the edge. The suction blower sucks the air at a ratio of 1:1.5 atmospheric air's in order to increase or maintain the pressure that is to be maintained in the gasifier. The main purpose of the suction blower is to provide enough supply of air for the complete oxidation thereby increases the efficiency of the gasifier.

\section{E. Gas burner}

The burner gas stove used for the experimental purpose is normal stainless LPG gas stove which is $14 * 14 * 6$ inch.

\section{F. Chemical analysis}

The Proximate analysis for Prosopis Juliflora sample was analysed using the methods mentioned by Jagadeeshkumar et. al., [7]. Briefly, the moisture content of the sample was determined by the oven method (ASTM-E871), where $3 \mathrm{~g}$ of powdered sample of biomass was taken in a petri dish and kept inside the oven with a set temperature of $105^{\circ} \mathrm{C}$ for $24 \mathrm{~h}$. The moisture content was calculated by measuring weight of moisture escaped from sample and original sample. The volatile matter of the sample was determined using muffle furnace following the standard procedure (ASTM- E872). The muffle furnace was maintained at $650^{\circ} \mathrm{C}$ and the sample was kept in it for six minutes and then the temperature was ramped up to $750^{\circ} \mathrm{C}$ and placed the sample for another six minutes. The volatile matter (\%) was found out from the loss in weight of the sample. The ash content of the selected sample was found out (ASTM, E-830) by taking a known quantity of dried sample in an open crucible and keeping it in a muffle furnace at about $750^{\circ} \mathrm{C}$ up to reaching a standard weight. With ash content and the volatile matter, the fixed carbon of the sample was calculated using the equation (1). Fixed carbon, $\%=100-($ volatile content $(\%)+$ ash content $(\%))$

(1)

The efficiency of a fuel can be understood by determining its calorific value. The Calorific value of biomass was determined by using the bomb calorimeter and the instructions described by Jagadeeshkumar et. al., [3]. The calorific value of a fuel is defined as the amount of heat liberated, when a unit mass of fuel is burnt completely.

\section{RESULTS AND DISCUSSION}

A. Characteristic comparison of Prosopis Juliflora and coconut shell

The biomass used for the performance analysis of gasifier is Prosopia juliflora $(5 \mathrm{~mm})$, coconut shell. Thermal properties of biomass are given in the Table.1.

TABLE I. THERMAL PROPERTIES OF BIOMASSS

\begin{tabular}{|l|c|c|}
\hline \multicolumn{3}{|c|}{ Characteristic analysis and comparison } \\
\hline \multicolumn{1}{|c|}{ Characteristics } & PJ (5mm) & $\begin{array}{c}\text { Coconut } \\
\text { shell }\end{array}$ \\
\hline Mositure content (\%) & 9.40 & 10.53 \\
\hline Volatile matter (\%) & 83.05 & 57.96 \\
\hline Ash Content (\%) & 1.7 & 18.4 \\
\hline Fixed Carbon $(\%)$ & 15.78 & 13.10 \\
\hline Bulk Density $\left(\mathrm{kg} / \mathrm{m}^{3}\right)$ & 395 & 480 \\
\hline Calorific Value $(\mathrm{kcal} / \mathrm{kg})$ & 4952 & 5500 \\
\hline
\end{tabular}

\section{B. Thermogravimetric analysis (TGA)}

TGA is a process in which the physical and chemical properties of biomass is determined as a functions of increasing temperature with respect to the constant heat rate 
or vice versa. TGA is most commonly used to exhibit weight loss or gain due to oxidation, decomposition or loss of volatiles.

\section{Thermogravimetric analysis of Prosopis Juliflora}

In TGA analysis, generally the moisture content removal will begin at $250^{\circ} \mathrm{C}$ and will last for $30 \mathrm{~min}$. The loss of volatile will get initiated at this temperature and will last up to $350^{\circ} \mathrm{C}$. For the PJ, the moisture removal initiated at $250{ }^{\circ} \mathrm{C}$ and lasted for 22 minutes. The release of lighter volatile initiated at $250^{\circ} \mathrm{C}$ and last up to $380^{\circ} \mathrm{C}$ which accounted for $30 \%$ of the PJ used for the analysis. Based on this TGA analysis, the oxidation temperature of $P J$ was found to be around $390^{\circ}$ C. Similarly the TGA for the coconut shell showed that the moisture content removal was initiated at $260^{\circ} \mathrm{C}$ and lasted for $30 \mathrm{~min}$. The release of lighter volatiles initiated at $260^{\circ} \mathrm{C}$ and lasted up to $538^{\circ} \mathrm{C}$. And based on this analysis, the oxidation temperature for the coconut shell was observed to be around $600^{\circ} \mathrm{C}$.

\section{Performance analysis of gasifier}

The performance analysis of gasifier is monitored for 7 days. The capacity of gasifier is $100 \mathrm{~kg} / \mathrm{hr}$. the temperature of producer gas is $300^{\circ} \mathrm{C}-500^{\circ} \mathrm{C}$. The producer gas emitted from the gas outlet enters into the chilled scrubber. High temperature gas is chilled and some particulate matter present in the gas got removed. About $15-20 \%$ of the dust particles was removed from the gas in the scrubber unit. The cool gas enters into wet scrubber. About $65-75 \%$ of heavy particulate matters were removed. In order to avoid tar coagulation and to get dust free producer gas two fabric filters were attached in with tar content is filtered up to $50-97 \%$ step by step. Suction blower is used to suck the atmospheric air in the ratio of $1: 1.5$, and used to increase the pressure to the required level. Gasifier is used at the maximum of about 16-17 hrs. The overall efficiency of gasifier was estimated as $80 \%$. Significant increase in the calorific value of the producer gas was achieved by supplying air through the suction blower for gasification. Ash removal grater was introduced in order to minimize the charcoal removal rate and also to increase gas efficiency.

\section{CONCLUSION}

Since Prosopis Juliflora has traditionally been used in India as cooking fuel. The present investigation proves that the conversion efficiency is only $20 \%$ under open combustion in the traditional stoves. However the gasification of Prosopis Juliflora gives encouraging results and the thermal efficiency reached up to $80 \%$. Experiments have also been carried out for directly admitting the producer gas for cooking purpose which makes real environmental sustainability of rural areas.

\section{REFERENCES}

[1] Panwar, N.L., Rathore, N.S., Environment friendly biomass gasifier cookstoves for community cooking. Environ Technol. 2015; 36(18):2308-2311

[2] Kumari, H., Rethinking biomass cook stove innovations and issues International journal for research in applied science and engineering technology. 2016; 4(3):608

[3] Kumar, A., Jones, D. D., Hanna, M. A., Thermochemical biomass gasification: A review of the current status of the technology. Energies. 2009;2:556-581

[4] Pathak, P.S., Khan, T.A., Sharma, P., Biomass production, its utilisation and surplus for energy generation in India, Proceedings of the national seminar on Biomass management for energy purposeissues and strategies. SPRERI, 2004, pg.10-15

[5] Yang, V., Sharifi and Swithenbank, J., Effect of air flow rate and fuel moisture on the burning behaviours of biomass and simulated municipal solids wastes in packed beds. Fuels. 2004;83:1553-1562

[6] Saraswathi, K., Chandrasekaran, S., Biomass yielding potential of naturally regenerated Prosopis Juliflora tree stands at three varied ecosystems in southern districts of Tamil Nadu, India. Environ. Sci pollut Res Int. 2016;23(10):9440-9447.

[7] Jagadeeshkumar, K., and Kamaraj, S., (2015) Design of biogas stove for frying chips and effective utilization of cashew nut shell for gasification, IJERT: 4(5): 361-364.

[8] Sarbjeet Singh Sooch* and Anand Gautam (2012) Present Status of Renewable Energy Sources in Punjab, IJAEB: 6(2): 317-333.

[9] Sridhar Samudrala. (2011) India energy Handbook. 2011. <http://www.psimedia.info/handbook/India_Energy_Handbook.pdf>. 